\title{
A Comparative Study of Stapled Vs Subcuticular Vs Simple Interrupted Closure of Inguinal Hernia Incision
}

\author{
Geeta S. Ghag ${ }^{1}$, Kamal S. Shukla ${ }^{2}$, Ankur Karanjkar ${ }^{3}$, Dhirajkumar B. Shukla ${ }^{4}$ \\ ${ }^{I}$ Associate Professor, Department of Surgery, HBT Medical College and Dr. R. N. Cooper Hospital, Mumbai \\ ${ }^{2}$ Assistant Professor, Department of Surgery, HBT Medical College and Dr. R. N. Cooper Hospital, Mumbai \\ ${ }^{3}$ Resident, Department of Plastic and Reconstructive Surgery, B.J. Medical College and Sassoon General \\ Hospital, Pune \\ ${ }^{4}$ Assistant Professor, Department of Pathology, Krishna Institute of Medical Sciences University, Karad.
}

\begin{abstract}
:
Introduction:Hernia repair is one of the most common surgical procedure performed by general surgeons. With increasing knowledge about accelerated rehabilitation, the surgeons are under pressure to reduce the duration of hospital stay, due to which the method of skin closure has gained importance. The two main techniques of skin closure used by surgeons, are removable skin staples and skin sutures. We decided to study the various skin closure techniques in hernia surgery.

Material and Method:The present study was a comparative study carried out at a tertiary care hospital over a period of two years. Total 90 patients of hernia were included in the present study. Patients were divided into 3 groups based on the method of skin closure applied. Main parameters investigated were postoperative pain, postoperative wound infection rates, cosmetic acceptability of scar and time required for skin closure. Statistical analysis was used wherever applicable.

Results:The incidence of hernia is common in the younger age group, the mean age being in the 4lyears. The majority of cases were unilateral (right side); right sided indirect inguinal hernia was the most frequent type observed in this study. At 48 hrs both stapled and subcuticular group have comparable but not significant pain i.e. they experienced only mild, nagging pain. At discharge Subcuticular closure group has significantly less pain. At 48 hrs, highest wound infection rate was in subcuticular group (60\%). 73.3\% of patients having skin closure using stapler didn't had any wound infection at $48 \mathrm{hrs}$. At time of suture removal, highest number of wound complication occur in subcuticular group.

Conclusion:Subcuticular closure of inguinal skin incision gives best cosmetic scar to patients. Subcuticular skin closure technique is painless. Skin Stapler is most rapid method of skin closure. Least wound complications are with use of skin stapler.
\end{abstract}

Keywords:Hernia, Staple, Suture, Subcuticular

\section{Introduction}

With the development of accelerated rehabilitation and the pressure placed on surgeons to reduce length of stay in hospital, the method of skin closure has become increasingly important. Wound complications are one of the major sources of morbidity after any surgical procedures and can prolong the inpatient stay or lead to re-admission ${ }^{(1)}$.

Many operations are available in a general surgeon's armamentarium that of hernia repairs has been written about repeatedly. It is estimated that at least 5\% of the population will develop a groin hernia in their lifetime, making groin hernia repair one of the most common operations performed by general surgeons. In some countries Inguinal Hernia surgeries are most common elective operations performed by general surgeons (2). There are many techniques available for inguinal hernia repair; skin closure remains limited to two main techniques, either by using removable skin staples or skin sutures. The most commonly used methods for skin closure after surgery are metal staples or sutures. Both methods act to hold the skin edges together while healing occurs. ${ }^{(2)}$ We decided to study the various skin closure techniques in hernia surgery, with the aim to study which type of wound closure is simple, fast, tension free with no subsequent adverse reactions, creation of protective barrier to pathogens has a simple post-operative management, simple for suture removal and optimal cosmetic appearance $^{(3)}$. and cost effectiveness ${ }^{(4)}$.

\section{Materials and methods}

The present study is a comparative Study carried out in a tertiary care centre over a period of two years. Total 90 patients of inguinal hernia were included in the study. Out of 90 patients, 30 patients allotted to each group by random envelope allocation method and into 3 groups. The study was approved by the local research ethics committee. 
GROUP A: Stapled skin closure

GROUP B: Subcuticular skin closure

GROUP C: Simple Interrupted skin closure

\section{Suture Material Used:}

Non-absorbable Monofilament Polyamide black 3-0 RC (reverse cutting)

Skin Stapler (Ethicon, Proximate)

\section{Inclusion Criteria:}

- With diagnosis of Inguinal Hernia

- Age between 18 to 65 years of either sex

- Normal Body Mass Index

- Ready to give written informed consent were considered.

\section{Exclusion Criteria:}

- Age less than 18 years OR more than 65 years

- Complicated hernia such as bowel obstruction, bowel strangulation, peritonitis, bowel perforation, local and systemic infection

- Recurrent hernia

- Sero-status positive (HIV and HBsAg infection)

- Diabetes mellitus

- On chemotherapy, immuno-suppressants, and steroid medication were not considered in study.

Main parameters investigated were postoperative pain, postoperative wound infection rates, cosmetic acceptability of scar and time required for skin closure.The diagnosis of inguinal hernia was made by clinical examination.The preoperative evaluation included history, clinical findings, and routine lab investigations.Body mass index was calculated.Ultrasonographic evaluation of the abdomen was done in selected patients. X ray and ECG were done for patients above 40 years of age for anesthetic evaluation. Lichtenstein tension free repair with meshplasty with ilioinguinalneurectomy was done in all patients under general or spinal anesthesia. A single dose of preoperative broad spectrum antibiotic was given followed by the same for 3 days postoperatively. Information was gathered at operation on whether the hernia was anatomically direct, indirect or pantaloons. The time taken for skin closure with staples or subcuticlar sutures or simple interrupted sutures was measured in seconds. Post operatively wounds were covered with a padded occlusive dressing with micropore. Analgesics were given postoperatively for 2 days. Post-operative pain was recorded by using Visual Analog Scale (0-10; 0- Best, 10-Worst) at 48 hrs. and at time of discharge. An independent assessor examined the wound at $48 \mathrm{hrs}$. and at the time of suture or staples removal for any cutaneous signs of infection. Both staples and sutures were removed at 10 days. Wound infection grades used were $(0-4)$ as follows:

0- None

1- Erythema / Induration / Stich Abscess

2- Exudates / Subcutaneous Abscess

3- Partial dehiscence

4- Complete dehiscence

Cosmetic acceptability of scar was assessed by independent assessor at 6 weeks during follow up examination. Scar assessment scale wasPatient and Observer Scar Assessment Scale (POSAS).The observer scale of the POSAS consists of six items (vascularity, pigmentation, thickness, relief, pliability and surface area).All items are scored on a scale ranging from 1 ('like normal skin') to 10 ('worst scar imaginable'). The sum of the six items results in a total score of the POSAS observer scale. Furthermore, an overall opinion was scored on a scale ranging from 1 to 10 . Statistical analysis was done wherever applicable using standard tests of significance.

\section{Results}

Over the past two years, we studied 90 consecutive cases of primary inguinal herniaand its skin closure at our Tertiary Health Centre. The data was collected and tabulated in the form of a Master chart and various parameters studied.

These patients randomly divided into three groups for comparison, with 30 patients each in Group A (Stapled), Group B (Subcuticular) and Group C (Simple interrupted). On analysing data we obtained the following results. 
The Age wise distribution of the cases of Primary inguinal hernia skin closure in ourTertiary Health Centre were as follows:

Table 1: Mean Age Distribution

\begin{tabular}{|l|l|l|l|}
\hline Parameters & Group A & Group B & Group C \\
\hline No. of cases & 30 & 30 & 30 \\
\hline Age (yrs.) & & & \\
Mean & 40.93 & 40.10 & 41.93 \\
SD & 14.05 & 13.21 & 13.22 \\
Range & $20-64$ & $20-62$ & $19-63$ \\
\hline
\end{tabular}

By AnovaP > 0.05, Not Significant

The age distribution of the patients in the study was taken into consideration. As we found the graph plot below, average age being 40.93 years among Group A (Stapled), which was comparable to 40.10 and 41.93 years among Group B (Subcuticular) \& C (Simple Interrupted) respectively. In our study group age of the cases were ranging from $19-64$ years.

Table 2:Gender Distribution

\begin{tabular}{|l|c|c|c|}
\hline Gender & Group A & Group B & Group C \\
\hline Male (\%) & 100 & 100 & 100 \\
\hline Female (\%) & 0 & 0 & 0 \\
\hline
\end{tabular}

By Chi-Square Test $\mathrm{P}>0.05$, Not Significant

All patients were males. Over period of study, no female patient was presented with aforesaid inclusion criteria.

Table 3: Laterality of Inguinal Hernia

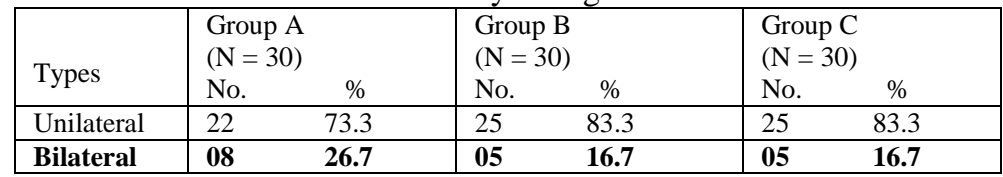

By Chi-Square, Test P $>0.05$, not significant

In our study, most of patients presented with unilateral inguinal hernia $(n=72$ i.e. $80 \%)$ and remaining were bilateral inguinal hernia $(n=18$ i.e.20\%). Twenty-five $(83.3 \%)$ cases, each had Unilateral inguinal hernia among subcuticular and simple interrupted closure group respectively, which was more as compared to 22 $(73.3 \%)$ of the cases among stapled group. Among 18 (20\%) of Bilateral inguinal hernia; 8 (26.7\%) were closed with stapled and remaining each $5(16.7 \%)$ were closed with subcuticular and simple interrupted, respectively. The difference was not significant.

Table 4: Operated Side of Inguinal Hernia

\begin{tabular}{|c|c|c|c|c|c|c|}
\hline Sides & $\begin{array}{l}\text { Gro } \\
\text { (N } \\
\text { No. }\end{array}$ & $\%$ & $\begin{array}{l}\text { Grol } \\
(\mathrm{N}= \\
\text { No. }\end{array}$ & $\%$ & $\begin{array}{l}\text { Grol } \\
(\mathrm{N}= \\
\text { No. }\end{array}$ & $\%$ \\
\hline Right & 18 & 60.0 & 21 & 70.0 & 20 & 66.7 \\
\hline Left & 12 & 40.0 & 09 & 30.0 & 10 & 33.3 \\
\hline
\end{tabular}

By Chi-Square, Test $\mathrm{P}>0.05$, Not significant

Above table states that; majority of patients were operated on right side $(n=59$ i.e. $65.55 \%)$ as compared to operations performed on left side $(n=31$ i.e. $34.54 \%)$.

Highest number of right sided inguinal hernia skin closure was in subcuticular group ( $\mathrm{n}=21$ i.e. $70 \%$.). It was comparable with number of cases among stapled group $(n=18$ i.e. $60 \%)$ and simple interrupted group $(n=20$ i.e. $66.7 \%)$. Among left sided inguinal hernia skin closure; Forty percent $(n=12)$ cases closed with stapler which was compared with $30 \%(n=09)$ and $33.3 \%(n=10)$ cases with subcuticular and simple interrupted closure, respectively. But difference was not significant.

Table 5: Type of Anaesthesia

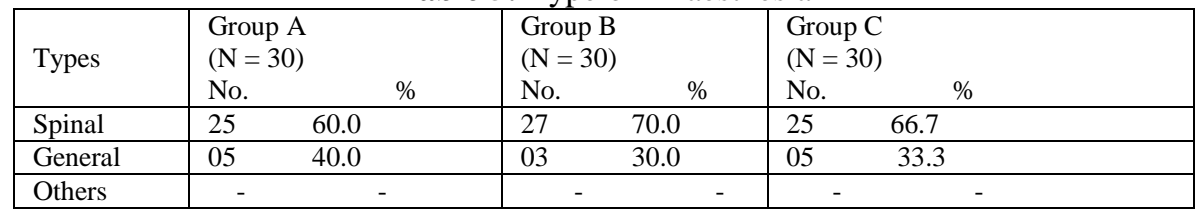

By Chi-Square Test $\mathrm{P}>0.05$, not significant 
As per this table, predominant anaesthesia used was spinal $(n=77$ i.e. $85.55 \%)$. Out of all cases, only 13 $(14.45 \%)$ were operated under general anaesthesia. None of the patient was operated under other form of anaesthesia (epidural, local).

This group wise data reveals that, $70.0 \%$ of cases were operated with Spinal anaesthesia among subcuticular group, which was more as compared to $60.0 \%$ and $66.7 \%$ of the cases among stapled group and simple interrupted group respectively, but difference was not significant.

Table 6: Intra-Operative Findings

\begin{tabular}{|c|c|c|c|c|c|c|}
\hline Types & \multicolumn{2}{|c|}{$\begin{array}{l}\text { Group A } \\
(\mathrm{N}=30)\end{array}$} & \multicolumn{2}{|c|}{$\begin{array}{l}\text { Group B } \\
(\mathrm{N}=30)\end{array}$} & \multicolumn{2}{|c|}{$\begin{array}{l}\text { Group C } \\
(\mathrm{N}=30)\end{array}$} \\
\hline Direct & 05 & 16.7 & 11 & 36.7 & 10 & 33.3 \\
\hline Indirect & 16 & 53.3 & 15 & 50.0 & 15 & 50.0 \\
\hline Both & 09 & 30.0 & 04 & 13.3 & 05 & 16.7 \\
\hline
\end{tabular}

By Chi-Square Test $\mathrm{P}>0.05$, not significant

Above profile reveals that, in our study; 46 patients found to be have indirect hernia intraoperative. (51.11\%).Among remaining 44 patients, 26 were have direct hernia sac $(28.88 \%)$ and 16 were have both sacs i.e. pantloon hernia (17.77\%). $16.7 \%$ of the cases had direct sac as intra operative findings among stapled group, which was less as compared to $36.7 \%$ and $33.3 \%$ of the cases among subcuticular and simple interrupted group respectively, but difference was not significant.

$53.3 \%$ of the cases had indirect sac as intra operative findings among stapled group, which was more as compared to $50 \%$ each of the cases among subcuticular and simple interrupted group respectively, but difference was not significant.

Table 7:Post - Op Pain by using VAS Score between the groups

(At $48 \mathrm{hrs)}$
\begin{tabular}{|c|l|}
\hline Groups & $\begin{array}{l}\text { Mean VAS score } \\
\left(\overline{\mathrm{X}}_{ \pm} \mathrm{SD}\right)\end{array}$ \\
\hline $\mathrm{A}(\mathrm{N}=30)$ & $3.07+1.31$ \\
\hline $\mathrm{B}(\mathrm{N}=30)$ & $2.97+0.61$ \\
\hline $\mathrm{C}(\mathrm{N}=30)$ & $* 3.87+0.73$ \\
\hline Total $(\mathrm{N}=90)$ & $03.30 \pm 01.01$ \\
\hline P value & $* 0.004$ \\
\hline
\end{tabular}

By Anova (Bonferonni Test) * *ignificant

This analysis states that mean overall VAS Score at 48 hrs was 3.30.

Mean VAS score at $48 \mathrm{hrs}$ was 3.87 among simple interrupted group, which was significantly more ( $p$ value $=0.004$ ) as compared to 3.07 and 2.97 among stapled group and subcuticular group respectively.

It showed that patients having simple interrupted closure complained uncomfortable, troublesome nagging pain at $48 \mathrm{hrs}$. opposed to rest two groups which had only mild, annoying pain. significant.

Where as in stapled and subcuticular group mean VAS score was comparable and difference was not

Table 8: Post - Op pain by using VAS score between the group(At discharge)

\begin{tabular}{|l|l|}
\hline Groups & $\begin{array}{l}\text { Mean VAS score } \\
\overline{\mathrm{X}} \pm \mathrm{SD})\end{array}$ \\
\hline $\mathrm{A}(\mathrm{N}=30)$ & $1.80+1.56$ \\
\hline $\mathrm{B}(\mathrm{N}=30)$ & $* 1.13+1.36$ \\
\hline $\mathrm{C}(\mathrm{N}=30)$ & $1.87+1.22$ \\
\hline Total $(\mathrm{N}=90)$ & $01.60 \pm 01.41$ \\
\hline $\mathrm{P}$ value & $* 0.026$ \\
\hline
\end{tabular}

As per the above data, Mean VAS score at discharge was 1.13 among Subcuticular closure group, which was significantly less $(p=0.026)$ as compared to 1.80 and 1.87 among stapled and simple interrupted group respectively. At time of discharge patients with subcuticular closure had pain which was almost negligible in contrast to other both groups have mild, annoying pain at discharge, where as in stapled and simple interrupted group pain score was comparable and difference was not significant at time of discharge.

Mean overall VAS score at discharge was 1.60 
Table 9:Wound Infection Rate between the groups (at $48 \mathrm{hrs}$ )

\begin{tabular}{|c|c|c|c|}
\hline Grade & $\begin{array}{l}\text { Group A } \\
(\mathrm{N}=30) \\
\text { No. }\end{array}$ & $\begin{array}{l}\text { Group B } \\
(\mathrm{N}=30) \\
\text { No. }\end{array}$ & $\begin{array}{l}\text { Group C } \\
(\mathrm{N}=30) \\
\text { No. }\end{array}$ \\
\hline 0 & $* 22 \quad 73.3$ & $\begin{array}{ll}12 & 40.0\end{array}$ & $\begin{array}{ll}18 & 60.0\end{array}$ \\
\hline 1 & 26.7 & 50.0 & 40.0 \\
\hline 2 & - & 10.0 & - \\
\hline 3 & - & - & - \\
\hline Infection rate & $26.7 \%$ & $60.0 \%$ & $40.0 \%$ \\
\hline $\begin{array}{l}\text { Overall Wound } \\
\text { Infection Rate }\end{array}$ & & $42.2 \%$ & \\
\hline
\end{tabular}

By Chi-Square Test $\mathrm{P}$ value $=0.03, *$ Significant

Above data reveals that, Overall wound infection rate was $42.2 \%(\mathrm{n}=38)$.At 48 hrs. highest wound infection rate was in subcuticular group $(60 \%)$ followed by simple interrupted group (40\%) and least in stapled group (26.7\%).73.3\% of patients having skin closure using stapler didn't have any wound infection at 48 hrs. This was significant $(p=0.03)$ as compared to other two groups. Wound infection rates between subcuticular and simple interrupted group were comparable but difference was not significant.In stapled group, at $48 \mathrm{hrs,} \mathrm{eight}$ patients $(26.7 \%$ ) had wound infection in form erythema (Grade 1).In subcuticular group, 60\% patients had wound infection at $48 \mathrm{hrs}$. Out of which, 15 patients had erythema or induration (Grade 1) and 3 patients had Grade wound infection in form of exudates.Twelve patients of simple interrupted group had erythema (Grade 1) at $48 \mathrm{hrs}$.None of the patient had partial or complete dehiscence of wound.

Table 10:Wound Infection Rate between the groups (Atsuture removal)

\begin{tabular}{|c|c|c|c|c|c|c|}
\hline Grade & \multicolumn{2}{|c|}{$\begin{array}{l}\text { Group A } \\
(\mathrm{N}=30)\end{array}$} & \multicolumn{2}{|c|}{$\begin{array}{l}\text { Group B } \\
(\mathrm{N}=30)\end{array}$} & \multicolumn{2}{|c|}{$\begin{array}{l}\text { Group C } \\
(\mathrm{N}=30)\end{array}$} \\
\hline 0 & 18 & 60.0 & 16 & 53.3 & 18 & 60.0 \\
\hline 1 & 07 & 23.3 & 05 & 16.7 & 04 & 13.3 \\
\hline 2 & 05 & 16.7 & 04 & 13.3 & 08 & 26.7 \\
\hline 3 & - & - & 05 & 16.7 & - & - \\
\hline Infection rate & 40.0 & & 46.7 & & 40.0 & \\
\hline Overall Wound Infection Rate & & & 42.2 & & & \\
\hline
\end{tabular}

By Chi-Square Test, $\mathrm{P}>0.05$, not significant

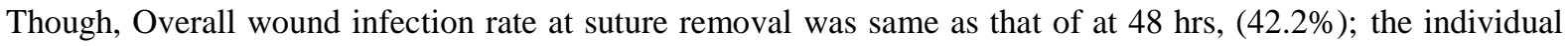
differences among groups were comparable but notsignificant $(p>0.05)$. At time of suture removal, highest number of wound complication occurred in subcuticular group $(n=14$ i.e. $46.7 \%)$. Only this group had grade 3 infection in form of partial dehiscence $(n=5)$. Both remaining groups had equal number of wound infection $(\mathrm{n}=12$ i.e. $40 \%)$ at time of suture removal. But rate of Grade 2 (exudates or subcutaneous abscess) was more with simple interrupted closure. $(26.7 \%$ vs $16.7 \%)$

Table 11: Cosmetic Acceptability of Scar (Total POSAS Score)

\begin{tabular}{|c|c|}
\hline Groups & $\begin{array}{c}\text { Mean total score } \\
\left(\overline{\mathrm{X}}_{ \pm \mathrm{SD}}\right)\end{array}$ \\
\hline $\mathrm{A}(\mathrm{N}=30)$ & $24.30 \pm 3.96$ \\
\hline $\mathrm{B}(\mathrm{N}=30)$ & $* 13.53 \pm 2.78$ \\
\hline $\mathrm{C}(\mathrm{N}=30)$ & $23.87 \pm 3.05$ \\
\hline $\mathrm{P}$ value & 0.002 \\
\hline
\end{tabular}

By Anova (Bonferonni Test) * Significant

Cosmetic appearance of scar was found best in subcuticular group with mean Total POSAS Score (13.3 \pm 2.78$)$ which was significantly less $(p=0.002)$ as compared to 24.30 and 23.87 among stapled and simple interrupted group respectively.

Table 12: Cosmetic Acceptability of Scar (Overall POSAS Score)

\begin{tabular}{|l|l|}
\hline Groups & $\begin{array}{l}\text { Mean overall score } \\
\left.\overline{\mathrm{X}}_{ \pm \mathrm{SD}}\right)\end{array}$ \\
\hline $\mathrm{A}(\mathrm{N}=30)$ & $5.03 \pm 1.25$ \\
\hline $\mathrm{B}(\mathrm{N}=30)$ & $* 2.23 \pm 0.43$ \\
\hline $\mathrm{C}(\mathrm{N}=30)$ & $3.97 \pm 0.49$ \\
\hline $\mathrm{P}$ value & 0.003 \\
\hline
\end{tabular}

By Anova (Bonferonni Test)* Significant 
Overall cosmetic appearance of scar was found best in subcuticular group with mean Overall POSAS Score $(2.23 \pm 0.43)$ which was significantly less $(p=0.003)$ as compared to 5.03and 3.97among stapled and simple interrupted group respectively. Whereas Overall appearance of scar in simple interrupted group was better than stapled group (3.97 vs 5.03) and difference was statistically significant.

Table 13: Time required for Skin Closure

\begin{tabular}{|l|l|}
\hline Group & $\begin{array}{l}\text { Mean Time required }(\mathrm{Sec} .) \\
\left(\mathrm{X}_{ \pm \mathrm{SD}}\right)\end{array}$ \\
\hline $\mathrm{A}(\mathrm{N}=30)$ & $* 044.63 \pm 47.23$ \\
\hline $\mathrm{B}(\mathrm{N}=30)$ & $459.93 \pm 59.29$ \\
\hline $\mathrm{C}(\mathrm{N}=30)$ & $193.33 \pm 55.47$ \\
\hline P value & 0.005 \\
\hline
\end{tabular}

By Anova (Bonferonni Test)* Significant

As per the analysis, average time required for skin closure was least with stapler $44.63 \mathrm{sec}( \pm 47.23)$ which was significant as compared to $459.93 \mathrm{sec}$ in subcuticular group and $193.33 \mathrm{sec}$ in simple interrupted closure. Whereas closure with simple interrupted was quicker compared to subcuticular and the difference was statistically significant.

\section{Discussion}

In our comparative study, we compared three of commonly used methods of skin closure of Primary Inguinal hernia skin incision.We compared 3 methods (Stapled, Subcuticular and Simple interrupted) without control group depending on specificstatistical tests (ANOVA, Chi-square test) which are used for different variables.

At the end of 2 years and after studying 90 consecutive cases of inguinal hernia skin incision, we made these inferences-

\section{Patient's Characteristics} distribution.

One of the most striking epidemiological features of inguinal hernia repair is its age and sex

In our study, differences among age and sex were not significant and did not affect the results of other variables. The mean age in stapled group was 40.93 yrs. In subcuticular group was 40.10 yrs. and that of in simple interrupted group was 41.93 .

This is comparable with the randomized controlled study by Malekpour F et al ${ }^{(5)}$ wherein the mean study age was $45 \pm 18$ years.

Overwhelming majority of inguinal hernia occur in males as compared to females. Of inguinal hernia repairs, $90 \%$ are performed in males and $10 \%$ in females. As in prospective randomised trial by Brown $\mathrm{JK}^{(3)}$ et. al.patients were predominantly male $(82 \%)$. Over period of study, no female patient was presented with aforesaid inclusion criteria in our study. Incidence of inguinal hernia in males has a bimodal distribution with peak before 1 year of age and then again after age 40 .

So, in our study; all result are attributed to male patients and hence comparison with female population is not possible.

Most of patients presented with unilateral inguinal hernia $(n=72$ i.e. $80 \%)$ and remaining were bilateral inguinal hernia $(n=18$ i.e. $20 \%)$. Majority of patients were operated on right side $(n=59$ i.e. $65.55 \%)$ as compared to operations performed on left side (n=31i.e.34.54\%).Laterality and operated side of hernia doesn't affect the final outcome of closure technique. In our study; 46 patients found to be have indirect hernia intraoperative. $(51.11 \%)$ Among remaining 44 patients, 26 were have direct hernia sac $(28.88 \%)$ and 16 were have both sacs i.e. pantloon hernia $(17.77 \%)$.

\section{Parameters:}

Pain:

Our study show that there was significantly more pain at $48 \mathrm{hrs}$ when the skin incision was closed with polyamide black 3-0 RC simple interrupted compared to staples or subcuticular closure. It is mostly attributed to free nerveendings of the pain modality in the superficial layers of the dermis and the germinal and granular zones of the epidermis are known to respond to physical deformity and a full thickness simple interrupted suture, when tied would embrace considerably more free nerve endings (pain). While a subcuticular or stapler bite atdermis/epidermis junction contains a small fraction of the corresponding nerve endings.

Where as in stapled and subcuticular group mean VAS score was comparable and difference was not significant at 48 hrs. But at time of discharge patients with subcuticular closure had pain which was almost

DOI: 10.9790/0853-15090197105 $\quad$ www.iosrjournals.org $\quad 102 \mid$ Page


negligible in contrast to other both groups have mild, annoying pain at discharge. This our findings are consistent with Mr. A Subramanianet.al. ${ }^{(6)}$ who found significantly more pain when inguinal skin incision is closed with staples. ALISTAIR B. CASSIE ${ }^{(7)}$ found less pain as with monofilament absorbable poly-dioxanone (PDS) as compared with non-absorbable polyamide black (Nylon). Frishman GN, Schwartz $\mathrm{T}^{(8)}$ reportedsignificantly less pain following subcuticular closure at both the time of discharge $(\mathrm{P}<$ or $=.01)$ and the postoperative visit $(\mathrm{P}<$ or $=.002)$ and his results are consistent with our results. Staples also caused pain while removing. According to Blackshaw G. ${ }^{(9)}$ skin closure with staple was much more painful.

\section{Wound Infection Rates:}

As per our analysis, we detected though overall wound infection rate was high (42.2\%); it was mostly grade 1 that means erythema. Wound infection rate was least significantly $(p=0.03)$ with use stapler in inguinal incision as opposed to rest of two suture techniques.

At time of suture removal five patients have partial dehiscence and all were belonged to suture group (subcuticular). Rate of Grade 2 (exudates or subcutaneous abscess) was more with simple interrupted closure as if edges are tightly opposed already, the oedema may compress capillaries and reduces blood supply. It leads delayed wound healing and may lead to wound infection.

There is a uniform agreement that skin wounds closed by staples exhibit superioresistance to infection than skin wounds contaminated by the least reactive sutureand added advantage of not crossing the wound edges as opposed to other suture technique.The superior resistance of stapled wounds to infection as compared with the resistance of sutured wounds was confirmed by the experimental study of

Stillman ${ }^{(10,11)}$ and colleagues. Iavazzo C, Gkegkes ID $^{(12)}$ foundfewer wound infection rates in the staples group compared with the sutures group(s) (12 studies, 1529 patients; odds ratio, 2.06; 95\% CI, 1.20 to 3.51 ).

Clay FS, Walsh $\mathrm{CA}^{(13)}$ found wound separation (pooled odds ratio, 4.01; $\mathrm{P}<.0001$ ) and composite wound complication (pooled odds ratio, $2.11 ; \mathrm{P}=.003$ ) rates were higher with staples. Mackeen $\mathrm{AD}^{(14)}$, Agbakwuru $\mathrm{EA}^{(15)}$,Lundbald $\mathrm{R}^{(16)}$, MR. A Subramanian ${ }^{(6)}$, and Eldrup ${ }^{(17)}$ et.al. found no difference in postoperative infection rates using staples or sutures.

\section{Cosmetic Acceptability of Scar:}

Cosmetic acceptability of scar was assessed by independent assessor at 6 weeks during follow up examination. Scar assessment scale wasPatient and Observer Scar Assessment Scale (POSAS).The observer scale of the POSAS consists of six items All items are scored on a scale ranging from 1 ('like normal skin') to 10 ('worst scar imaginable'). Both total and overall opinion was studied.Draaijers LJ, Tempelman FR, BotmanYA ${ }^{(18)}$ showed that POSASScale offers a suitable, reliable, and complete scar evaluation tool. Both Total and Overall POSAS score was significantly less ( $\mathrm{p}=0.002 \& \mathrm{p}=0.003$ respectively) in subcuticular group.Overall best cosmetic appearance of skin was with subcuticular followed by simple interrupted and comparatively worst with stapler. (2.23 vs 3.97 vs 5.03 respectively).

In a study comparing staples closure with nylon wound closure in head andnecksurgeries by Meiring ${ }^{(4)}$ et al showed that the cosmetic result of staples is asgood as if not better than that with nylon sutures.Lubowski D (19) et al compared stapledand sutured abdominal wound closurewhich resulted in almostequal cosmeticscores fo $r$ vertical wounds. No significant difference in wound appearances was conducted by $\mathrm{R}$ Bhatia ${ }^{(9)}$ et al in closure of palmar skin following Duyputrens contracture.

found in a study

Cromi A, Ghezzi F, Gottardi $\mathrm{A}^{(20)}$ et alcompared scar quality associated with either staples or 3 different types of subcuticular sutures in cesarean section. In the overall study population, objective scores correlated with patient rating, and correlation was strongest between the observer and patient components of the POSAS ( $\mathrm{r}$ $=0.4$ stapled wounds and those closed with subcuticular sutures result in equivalent cosmetic appearance of the scar.However in our study, it was found to be statistically significant.

Shetty et. al. ${ }^{(21)}$ subcuticular suture had better cosmetic scar appearance than skin clips in hip surgeries. A.N. OSUIGWEet. al. ${ }^{(22)}$ showed best cosmetic results with nylon subcutaneous contineous running sutures as compared with interrupted group.

Abu N.G.A. ${ }^{(23)}$ et al found that the skin staplers had better cosmetic scar appearance than subcuticular suture in prospective randomised trial for closure of scalp laceration in pediatric emergency department. Chughtai Tet. al. ${ }^{(24)}$ noted closure with a subcuticular technique achieves better outcomes than the use of skin clips.

\section{Time for Skin Closure:}

Average time required for skin closure was least with stapler $44.63 \mathrm{sec}( \pm 47.23)$ which was significant as compared to $459.93 \mathrm{sec}$ in subcuticular group and $193.33 \mathrm{sec}$ in simple interrupted closure.Meiring L.(4) et al found that time saving of $80 \%$ is possible with the stapling device but a certain amount of experience and practice facilitates its usage. Dos Santos $\mathrm{LR}^{(25)}$ et al undertook a prospective trial to investigate the advantages and disadvantages of stapled skin closure versus nylon sutures in head and neck surgery and even he found that

DOI: 10.9790/0853-15090197105 $\quad$ www.iosrjournals.org $\quad 103$ | Page


the use of skin staplers speeds up closure time by $80 \%$. Lubowski $\mathrm{D}^{(19)}$ found proximate staple closure was considered a suitable and faster method for vertical abdominal wounds as compared to sutures.

Mr. A Subramanian ${ }^{(6)}$ found the average time taken to close the skin using staples $(54 \pm 16$ seconds) was significantly shorter than using Prolene subcuticular (210 \pm 37 seconds) in inguinal hernia skin closure. This is comparable with our study in which Stapled closure required $44.63 \mathrm{sec}( \pm 47.23)$. In a study done by J. H. Wolterbeek et $\mathrm{al}^{(26)}$, they compared various methods of skinclosure in infra-inguinal bypass surgeriesand came to a conclusion thattime needed for wound closure is significantly reduced using metallic staples. Our results are also supported by other workers who found that, whilst operating time was significantly reduced when using staples rather than a non- absorbable subcuticular sutures. Alderdice F. ${ }^{(27)}$, Bhatia R. ${ }^{(9)}$, Frishman GN. ${ }^{(8)}$, Clay $\mathrm{FS}^{(13)}$, Walsh $\mathrm{CA}^{(13)}$ Gkegkes $\mathrm{ID}^{(12)}$, and et. al. found in meta-analysis regarding the time needed for wound closure, staples were superior to sutures; the mean difference observed between the sutures and staples groups was 5.56 minutes per wound which is comparable with 6.55 minutes in subcuticular group. The difference is because as subcuticular suture are difficult to place and require expertise.Simple interrupted closure is quick as compared to subcuticular.

\section{Conclusion}

The present study is a comparative study between stapled, subcuticular and simple interrupted inguinal hernia skin closure. The study was conducted with an intention to observe the effect of aforesaid skin closure technique on post-operative pain, wound complications, cosmetic acceptability of scar and time require for skin closure. We have drawn these important conclusions from our study:

$>$ Subcuticular closure of inguinal skin incision gives best cosmetic scar to patients.

$>$ Subcuticular skin closure technique is painless.

$>$ Skin Stapler is most rapid method of skin closure.

$>$ Simple interrupted skin closure is painful.

$>$ Least wound complications are with use of skin stapler.

$>$ Subcuticular skin closure is time consuming.

$>$ Wound complications are more with subcuticular skin closure.

\section{References}

[1]. Calabrese EJ. Historical foundations of wound healing and its potential for acceleration: dose-response considerations. Wound repair and regeneration : official publication of the Wound Healing Society [and] the European Tissue Repair Society. 2013;21(2):180-93.

[2]. Aabakke AJ, Krebs L, Pipper CB, Secher NJ. Subcuticular suture compared with staples for skin closure after cesarean delivery: a randomized controlled trial. Obstetrics and gynecology. 2013;122(4):878-84.

[3]. Brown JK, Campbell BT, Drongowski RA, Alderman AK, Geiger JD, Teitelbaum DH, et al. A prospective, randomized comparison of skin adhesive and subcuticular suture for closure of pediatric hernia incisions: cost and cosmetic considerations. Journal of pediatric surgery. 2009;44(7):1418-22.

[4]. Meiring L, Cilliers K, Barry R, Nel CJ. A comparison of a disposable skin stapler and nylon sutures for wound closure. South African medical journal = Suid-Afrikaanse tydskrif vir geneeskunde. 1982;62(11):371-2.

[5]. Malekpour F et.al. Ilio-inguinal nerve excision in open mesh repair of inguinal hernia-Results of a randomized clinical trial: Simple solution for a difficult problem. American journal of surgery. 2008;195(6):735-40.

[6]. Mr. SUBRAMANIAN MAHet.al. A Pospective Randomised Controoled Trial Comparing the use of Staples with Subcuticular Prolene Suture in Inguinal Hernia Incisions. The Journal of One-Day Surgery. 2006;vol. 15(No. 1):61-3.

[7]. Cassie AB, Chatterjee AK, Mehta S, Haworth JM. Pain quantum and wound healing: a comparison of interrupted inversion PDS and standard nylon sutures in abdominal skin closure. Annals of the Royal College of Surgeons of England. 1988;70(6):339-42.

[8]. Frishman GN, Schwartz T, Hogan JW. Closure of Pfannenstiel skin incisions. Staples vs. subcuticular suture. The Journal of reproductive medicine. 1997;42(10):627-30.

[9]. Bhatia R, Blackshaw G, Barr V, Savage R. Comparative study of "staples versus sutures" in skin closure following Dupuytren's surgery. Journal of hand surgery. 2002;27(1):53-4.

[10]. Richard M Stillman, Stephen J Seligman. Skin wound closure:The effect of various wound closure methods on susceptibility to infection. Arch Surg. 1980;115:674-78.

[11]. Stillman RM , Seligman SJ. Skin staples in potentially contaminated wounds. Archives of Surgery. Archives of Surgery. 1984, July;119(7):821-2.

[12]. Iavazzo C, Gkegkes ID, Vouloumanou EK, Mamais I, Peppas G, Falagas ME. Sutures versus staples for the management of surgical wounds: a meta-analysis of randomized controlled trials. The American surgeon. 2011;77(9):1206-21.

[13]. Clay FS, Walsh CA, Walsh SR. Staples vs subcuticular sutures for skin closure at cesarean delivery: a metaanalysis of randomized controlled trials. American journal of obstetrics and gynecology. 2011;204(5):378-83.

[14]. Mackeen AD, Berghella V, Larsen ML. Techniques and materials for skin closure in caesarean section. The Cochrane database of systematic reviews. 2012;11:CD003577.

[15]. Agbakwuru EA, Olabanji JK, Alatise OI, Katung IA, Onakpoya UU. Single versus two layer suturing for wound closure after inguinal hernia repair. Nigerian journal of clinical practice. 2009;12(2):162-4.

[16]. Lundblad R, Simensen HV, Wiig JN, Niels Gruner OP. [Skin closure. A prospective randomized study]. Tidsskrift for den Norske laegeforening : tidsskrift for praktisk medicin, ny raekke. 1989;109(12):1307-9.

[17]. Eldrup J WU, Andersen B. Acta Chir Scand 1981; 147(7): 501-2. Randomised trial comparing Proximate stapler with conventional skin closure. Acta Chir Scand. 1981;147(7):501-2. 
[18]. Draaijers LJ, Tempelman FR, Botman YA, Tuinebreijer WE, Middelkoop E, Kreis RW, et al. The patient and observer scar assessment scale: a reliable and feasible tool for scar evaluation. Plastic and reconstructive surgery. 2004;113(7):1960-5; discussion 6-7.

[19]. Lubowski D, Hunt D. Abdominal wound closure comparing the proximate stapler with sutures. The Australian and New Zealand journal of surgery. 1985;55(4):405-6.

[20]. Cromi A, Ghezzi F, Gottardi A, Cherubino M, Uccella S, Valdatta L. Cosmetic outcomes of various skin closure methods following cesarean delivery: a randomized trial. American journal of obstetrics and gynecology. 2010;203(1):36 e1-8.

[21]. Shetty AA, Kumar VS, Morgan-Hough C, Georgeu GA, James KD, Nicholl JE. Comparing wound complication rates following closure of hip wounds with metallic skin staples or subcuticular vicryl suture: a prospective randomised trial. J Orthop Surg (Hong Kong) 2004;12(2):191-193.

[22]. AN Osuigwe, CN Ekwunife, $\mathrm{CH}$ Ihekwoba. Skin closure after groin hernia repair in children: a comparative study of three suture materials and two suture techniques. African journal of urology. 2005;vol.11(no.4):282-6.

[23]. Khan AN, Dayan PS, Miller S, Rosen M, Rubin DH. Cosmetic outcome of scalp wound closure with staples in the pediatric emergency department: a prospective, randomized trial. Pediatr Emerg Care. 2002;18(3):171-173.

[24]. Chughtai T, Chen LQ, Salasidis G, Nguyen D, Tchervenkov C, Morin JF. Clips versus suture technique: is there a difference? The Canadian journal of cardiology. 2000;16(11):1403-7.

[25]. dos Santos LR, Freitas CA, Hojaij FC, Araújo Filho VJ, Cernea CR, Brandão LG, et al. Prospective study using skin staplers in head and neck surgery. Am J Surg. 1995;170:451-2.

[26]. Wolterbeek JH, van Leeuwen AA, Breslau PJ. Skin closure after infrainguinal bypass surgery: a prospective randomized study. Eur J Vasc Endovasc Surg. 2002;23:321-324.

[27]. Alderdice F, McKenna D, Dornan J. Techniques and materialsfor skin closure in caesarean section (Cochrane Review).TheCochrane Library2003, Issue 4.[Art. No.: CD003577. DOI:10.1002/14651858.CD003577] 